\title{
Odorant-Induced and Sniff-Induced Activation in the Cerebellum of the Human
}

\author{
Noam Sobel,, ${ }^{1}$ Vivek Prabhakaran, ${ }^{1}$ Catherine A. Hartley, ${ }^{2}$ John E. Desmond,, ${ }^{3}$ Zuo Zhao, ${ }^{3}$ Gary H. Glover, ${ }^{4}$ \\ John D.E. Gabrieli, ${ }^{1,3}$ and Edith V. Sullivan ${ }^{1,5}$ \\ Programs in ${ }^{1}$ Neuroscience and ${ }^{2}$ Symbolic Systems, and Departments of ${ }^{3}$ Psychology, ${ }^{4}$ Radiology, and ${ }^{5}$ Psychiatry and \\ Behavioral Sciences, Stanford University, Stanford, California, 94305
}

Functional magnetic resonance imaging was used to test whether odorants induce activation in the cerebellum of the human. The odorants vanillin and propionic acid both induced significant activation, primarily in the posterior lateral hemispheres. Activation was concentration-dependent, greater after stimulation with higher concentration odorants. By contrast, the action of sniffing nonodorized air induced significant activation in the anterior cerebellum, primarily in the central lobule. These findings demonstrate that the cerebellum plays a role in human olfaction. A hypothesis is proposed whereby the cerebellum maintains a feedback mechanism that regulates sniff volume in relation to odor concentration.

Key words: olfaction; cerebellum; sniffing; odor; smell; human
The cerebellum is a brain structure located at the back of the brain that in the human contains more neurons than the rest of the brain combined (Williams and Herrup, 1988). The cerebellum has classically been considered as primarily a motor control organ (Ito, 1984; Thach et al., 1992; Horne and Butler, 1995) with a specific role in motor learning (Lisberger, 1988; Lisberger et al., 1994). Recent functional imaging experiments in humans pointed to cerebellar involvement in a host of additional functions such as tactile sensory discrimination (Gao et al., 1996), attention (Allen et al., 1997), and cognitive function (Petersen et al., 1988; Kim et al., 1994; Raichle et al., 1994; Fiez, 1996; Parsons and Fox, 1997; Desmond et al., 1997, 1998; Poldrack et al., 1998; Schmahmann and Sherman, 1998).

Whereas cerebellar functions in visually and auditory related tasks have been extensively described (Snider and Eldred, 1948; Bloedel, 1973; Stein and Glickstein, 1992; Huang and Liu, 1991), no role has yet been suggested for the cerebellum in olfaction. This is surprising because olfaction is a sensory process largely dependent on the fine motor process of sniffing (Adrian, 1942; Le Magnen, 1945; Rehn, 1978; Mozell et al., 1983). Sniffing plays a major role not only in transport of the olfactory stimulus (Hahn et al., 1994) but also in patterns of neural activity in primary olfactory cortex in the human (Sobel et al., 1998). Furthermore, a fine reciprocal interaction persists whereby sniffing strategy and timing modulate odorant intake, and in turn, odorant intake content modulates further sniffing. For example, in response to increasing odorant concentration there is a decrease in sniff volume (Laing, 1983; Youngentob et al., 1987).

Cerebellar involvement in respiration (Mansfeld and Tyukody, 1936; Colebatch et al., 1991) suggests that sniff motor/sensory

\footnotetext{
Received June 16, 1998; revised Aug. 13, 1998; accepted Aug. 19, 1998.

N.S. was supported by an SGF Smith fellowship. E.V.S was supported by National Institutes of Health Grants AA10723 and AA05965. This work was made possible by Professor Lubert Stryer whom we thank for his advice and generosity. We also thank Rehan Khan for his advice (see World Book of Khans), Anne Sawyer, Jeff Wine, and Elite HaArak.

Correspondence should be addressed to Dr. Noam Sobel, Jordan Hall Building 420, Stanford University, Stanford, CA 94305.

Copyright (C) 1998 Society for Neuroscience $\quad 0270-6474 / 98 / 188990-12 \$ 05.00 / 0$
}

circuits may be in part controlled by cerebellar circuits. Thus, considering that odor content affects sniffing, odor content information may also be relayed to the cerebellum. Although preliminary reports using functional magnetic resonance imaging (fMRI) suggested that odorants may indeed activate the cerebellum (Yousem et al., 1997; Sobel et al., 1997a), this question has not been addressed in detail. Here we test whether odorants induce activation in the cerebellum and whether this activation would be dissociated from activation induced by sniffing.

Findings of cerebellar involvement in various tasks and modalities may still be explained within the framework of the cerebellum as a motor control system (Thach, 1996; Bloedel and Bracha, 1997), but they have also given rise to new theories of cerebellar function (Schmahmann, 1997). These include timing of motor performance (Ivry, 1997), coordinating acquisition of sensory data (Bower, 1997), neural representation of moving systems (Paulin, 1997), and facilitating attentional shifts (Courchesne et al., 1994; Akshoomoff et al., 1997). Elucidating a cerebellar role in olfaction may enable further characterization of the role of the cerebellum in relation to these theories.

\section{MATERIALS AND METHODS}

\section{Subjects}

Participants included nine men and eight women; all were right-handed and ranged in age from 20 to 39 (mean age, 25). Six subjects performed all three main experiments: two odorant tasks and a sniffing task. The remaining subjects performed one or two of the main experiments and the relevant control tasks. Each scanning session lasted $\sim 2 \mathrm{hr}$. The study was approved by the Stanford University Institutional Review Board, and all subjects signed informed consent.

\section{Stimuli and stimuli generation}

Methods of air dilution olfactometry were modified to accommodate the MRI environment (for methods in detail, see Sobel et al., 1997b). The system enabled switching from odorant to no odorant conditions in $<500$ msec. The alternation from odorant to no odorant conditions produced no auditory, visual, tactile, or thermal cues regarding the alteration between conditions. The odorants used were high ( $3 \% \mathrm{v} / \mathrm{v}$ in the liquid) and low $(0.3 \% \mathrm{v} / \mathrm{v})$ concentrations of vanillin $(\mathrm{VAN})$, and high $(5 \% \mathrm{v} / \mathrm{v})$, intermediate $(2 \% \mathrm{v} / \mathrm{v})$, and low $(0.5 \% \mathrm{v} / \mathrm{v})$ concentrations of propionic acid (PROP), both diluted in double-distilled deionized water. Whereas 


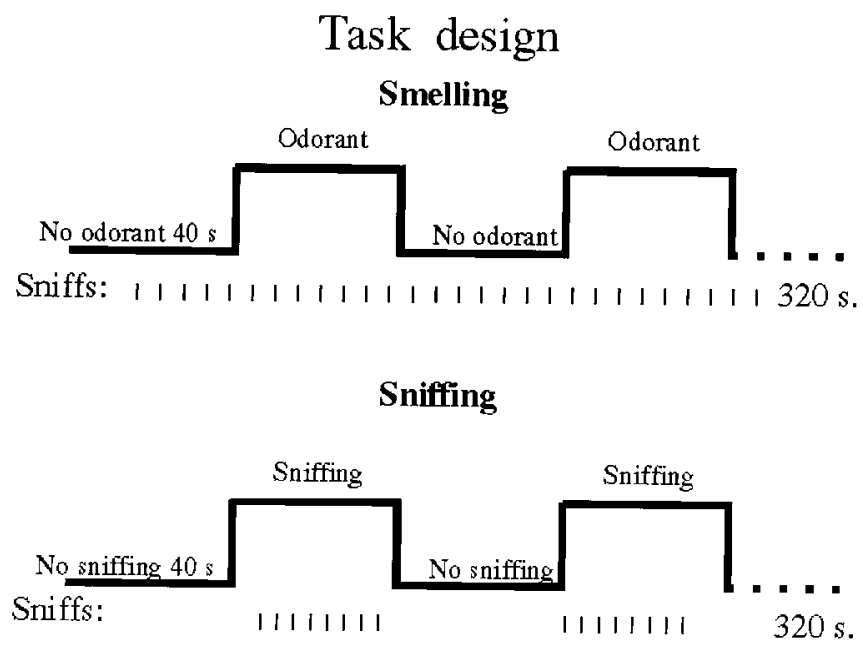

Figure 1. Task design of the smelling and sniffing tasks. Whereas in the smelling tasks sniffs constituted a constant baseline, and odorant presence alternated with odorant absence, in the sniffing task periods of sniffing alternated with periods of no sniffing.

VAN is a pure olfactant (Doty et al., 1978), PROP is an odorant with a strong trigeminal component (Kendal-Reed et al., 1998).

\section{Task design}

Smelling tasks. Alternating half blocks of diluent with odorant versus diluent only were generated (Fig. 1). Eight such $40 \mathrm{sec}$ half blocks, for a total duration of $320 \mathrm{sec}$ constituted a single scan. During a scan, a line of script reading: "Sniff and respond, is there an odor? Press the right button for yes or the left button for no" was projected to the subject once every $5 \mathrm{sec}$. Subjects sniffed and then responded by using the right index finger only to press one of two buttons. The number of sniffs and button presses was thus balanced over the odorant and the no odorant conditions, and constituted a constant baseline. The only difference between the half blocks was in the presence or absence of the odorant. Sniff duration was held constant by instructing the subjects to maintain the inhalation of the sniff for the duration of the projected message that was set to $800 \mathrm{msec}$. Response accuracy was recorded on a computer that controlled the olfactometer determining stimulus presence and triggered the scanner, thus maintaining synchronization between the task, stimulus presentation, and data acquisition.

Sniffing task. Alternating half blocks of sniffing versus no sniffing were generated (Fig. 1). Eight such $40 \mathrm{sec}$ half blocks, for a total duration of $320 \mathrm{sec}$ constituted a single scan. During a sniffing half block, a line of script reading: "Sniff" was projected every $5 \mathrm{sec}$ for $40 \mathrm{sec}$. During a no sniffing half block, a line of script reading "No sniff" was projected every $5 \mathrm{sec}$ for $40 \mathrm{sec}$. Sniff duration was held constant by instructing the subjects to maintain the inhalation of the sniff for the duration of the projected message that was set to $800 \mathrm{msec}$. The air sniffed in these tasks was clean air passed through active charcoal filters.

\section{Data acquisition}

In previous fMRI studies of the primary olfactory cortex, we used a slice orientation that serendipitously contained the cerebellum in the posterior tail of the acquisition (Sobel et al., 1997b, 1998). In these studies, in which we consistently noticed odorant-induced activation in the cerebellum, we used anteriorly placed surface coils for maximizing signal reception from primary olfactory regions. This led to a significant fMRI signal drop at the posterior end of the image that contained the cerebellum. We were, therefore, cautious in interpreting our initial findings of cerebellar activation. Here we use a slice orientation centered at the cerebellum combined with coil-placement maximizing cerebellar signal.

Imaging was performed using a $1.5 \mathrm{~T}$ whole-body MRI scanner (GE Signa, Revision 5.6 Echospeed). For functional imaging, a single 5-inchdiameter local receive coil was positioned centered at the inion under the back of the head. Head movement was minimized using a custom-built bite bar that was made to the dental impression of each subject. A T2*-sensitive gradient echo spiral sequence (Glover and Lai, 1998), which is relatively insensitive to cardiac pulsatility motion artifacts was

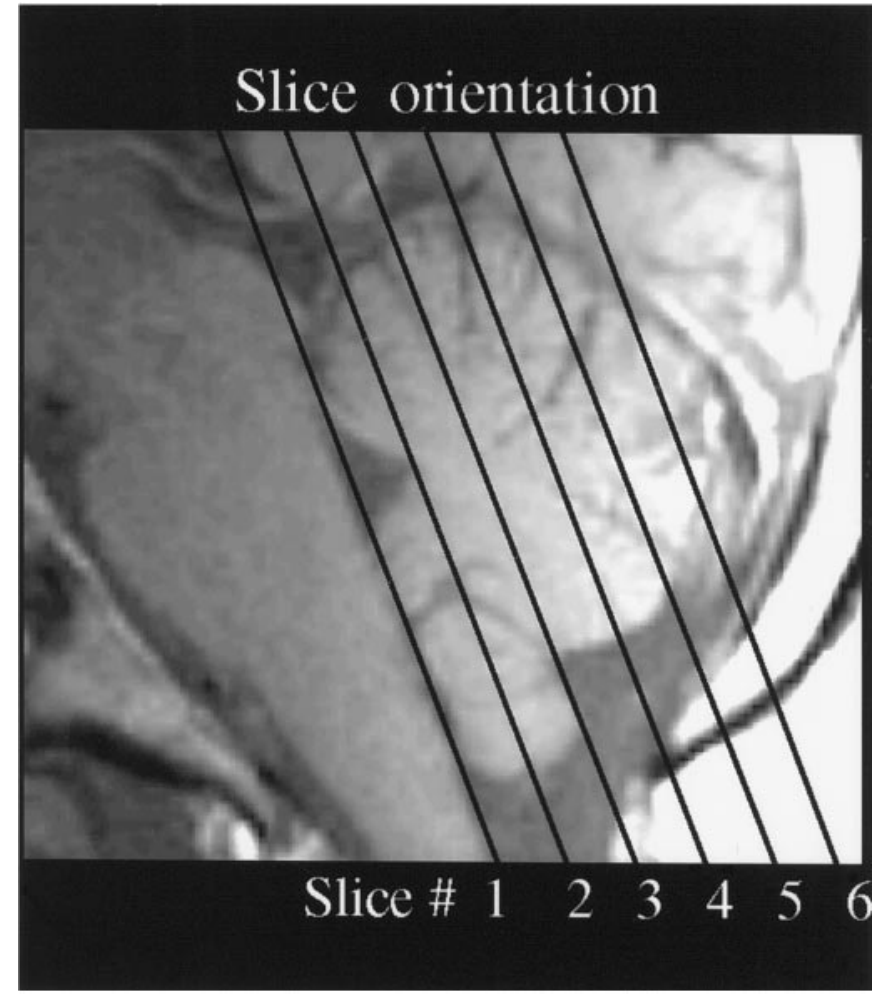

Figure 2. Six slices collected parallel to the brainstem

used with parameters of repetition time $(\mathrm{TR})=540 \mathrm{msec}$, echo time $(\mathrm{TE})=40 \mathrm{msec}$, flip angle $=60^{\circ}$. Spatial resolution was set by a $153 \times$ 153 voxel matrix covering a $36 \times 36 \mathrm{~cm}$ field of view resulting in an in-plane resolution of $2.35 \times 2.35 \mathrm{~mm}$. Four interleaves were collected for each frame, with total acquisition time of $2.16 \mathrm{sec}$ per frame; 153 frames were acquired for a total scan duration of $330.5 \mathrm{sec}$.

Six 5-mm-thick slices with a $1.5 \mathrm{~mm}$ interslice gap were acquired at an oblique coronal plane parallel to the brainstem (Fig. 2). The experimental sequence automatically initiated $10.5 \mathrm{sec}$ after scanning onset, allowing the first five frames to be discarded from the analysis. This eliminated transients arising before the achievement of dynamic equilibrium. T1weighted flow compensated spin-warp anatomy images (TR $=500 \mathrm{msec}$, minimum TE) were acquired at the same plane as a substrate on which to overlay functional data. For each subject, an additional acquisition of 20 T1-weighted flow-compensated spin-warp anatomy images was collected in the sagittal plane to later assist in the validation of localization of cerebellar regions.

\section{Analysis of functional data}

Analysis was performed using standard methods (Friston et al., 1994, 1996; Desmond et al., 1995, 1997). Image reconstruction was performed off-line on a Sun SparcStation. A gridding algorithm was used to resample the raw data into a Cartesian matrix before processing with twodimensional fast Fourier transform. Motion artifacts were assessed (Friston et al., 1996) and corrected (Woods et al., 1992). Once individual images were reconstructed, the time series of each pixel was correlated with a reference waveform and transformed into a $Z$ score map, SPM $\{Z\}$ (Friston et al., 1994). The waveform was calculated by convolving a square wave representing the time course of the alternating conditions (odorant/no odorant or sniffing/no sniffing) with a data-derived estimate of the hemodynamic response function. The frequency of the square wave in these experiments was four cycles $/ 320 \mathrm{sec}=0.0125 \mathrm{~Hz}$. SPM $\{Z\}$ map averaging and subject-by-subject-based region of interest (ROI) analysis were then used to analyze patterns of functional activation across subjects. Averaging was performed by first creating an outline of each oblique coronal section using a T1-weighted anatomy image of a representative subject to form a template for that slice. Then each subject's functional map at each section was transformed into the region specified by the template, as described by Desmond et al. (1997), using 
Table 1. ROI analysis

\begin{tabular}{|c|c|c|c|c|c|c|c|c|c|c|c|c|c|}
\hline \multirow[b]{2}{*}{ Region } & \multirow[b]{2}{*}{ Abbreviation } & \multicolumn{4}{|l|}{ PROP } & \multicolumn{4}{|l|}{ VAN } & \multicolumn{4}{|l|}{ Sniffing } \\
\hline & & $z$ & $\%$ & $r$ & $p$ & $z$ & $\%$ & $r$ & $p$ & $z$ & $\%$ & $r$ & $p$ \\
\hline Lobules-anterior vermis & Ave & 0.356 & 0.294 & 0.615 & 0.15 & 0.178 & 0.241 & 0.818 & 0.021 & 0.283 & 0.515 & 0.863 & 0.009 \\
\hline Biventer & $\mathrm{Bi}$ & 0.242 & 0.465 & 0.908 & 0.002 & 0.079 & -0.35 & 0.807 & 0.025 & 0.085 & -0.085 & 0.984 & 0.0001 \\
\hline Central lobule & $\mathrm{C}$ & 0.33 & 0.233 & 0.791 & 0.031 & 0.262 & 0.24 & 0.845 & 0.013 & 0.416 & 0.758 & 0.937 & 0.0006 \\
\hline Corpus medullare & $\mathrm{Cm}$ & 0.251 & 0.497 & 0.882 & 0.005 & 0.203 & 0.458 & 0.930 & 0.0009 & 0.049 & -0.526 & 0.967 & 0.0001 \\
\hline Dentate nucleus & $\mathrm{D}$ & 0.345 & 0.36 & 0.838 & 0.015 & 0.219 & 0.274 & 0.841 & 0.014 & -0.078 & -0.151 & 0.6 & 0.165 \\
\hline Gracile lobule & $\mathrm{Gr}$ & 0.285 & 0.982 & 0.894 & 0.004 & 0.122 & 0.193 & 0.922 & 0.001 & 0.08 & 0.127 & 0.971 & 0.0001 \\
\hline Nodulus & No & 0.415 & 0.077 & 0.855 & 0.01 & 0.273 & 0.124 & 0.506 & 0.264 & 0.367 & 0.056 & 0.908 & 0.0025 \\
\hline Lobules-posterior vermis & Pve & 0.423 & 0.281 & 0.641 & 0.12 & 0.318 & 0.221 & 0.916 & 0.001 & 0.069 & -0.128 & 0.993 & 0.0001 \\
\hline Anterior quadrangular lobule & Qua & 0.412 & 0.681 & 0.857 & 0.01 & 0.237 & 0.557 & 0.956 & 0.0001 & 0.1 & -0.249 & 0.862 & 0.009 \\
\hline Posterior quadrangular lobule & Qup & 0.507 & 2.177 & 0.881 & 0.005 & 0.325 & 1.894 & 0.841 & 0.014 & -0.153 & -1.216 & 0.824 & 0.019 \\
\hline Inferior semilunar lobule & SeI & 0.399 & 2.397 & 0.773 & 0.039 & 0.246 & 0.518 & 0.878 & 0.006 & -0.024 & 1.258 & 0.628 & 0.139 \\
\hline Superior semilunar lobule & $\mathrm{SeS}$ & 0.476 & 3.183 & 0.640 & 0.129 & 0.425 & 3.581 & 0.798 & 0.028 & -0.179 & -1.525 & 0.779 & 0.037 \\
\hline Tonsil & To & 0.243 & 0.244 & 0.925 & 0.001 & 0.172 & -0.088 & 0.838 & 0.015 & 0.041 & -0.431 & 0.890 & 0.004 \\
\hline
\end{tabular}

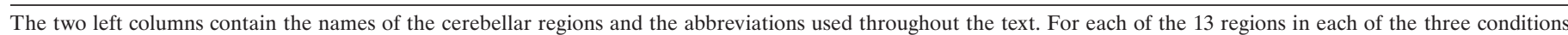

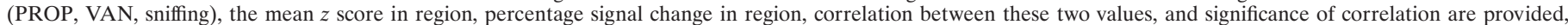

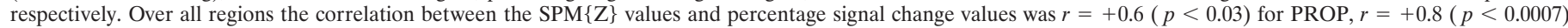
for VAN, and $r=+0.6(p<0.03)$ for sniffing.

the following steps: (1) translating, scaling, and rotating the functional map to match the centroid and dimensions of the template; (2) defining a matching set of points around the perimeter of the functional map and that of the template; (3) creating a grid of points from the perimeter points of the functional map and a corresponding grid on the template such that a one-to-one mapping existed for the grid points in each set; and (4) mapping the values from the grid points of the functional image to the grid points of the template. The resulting averaged functional activation maps were then intensity thresholded at a $p<0.01$ level (two-tailed), and each slice was subjected to a cluster analysis procedure (Xiong et al., 1995) to correct for multiple statistical comparisons, using a spatial extent threshold that yielded a $p<0.01$ significance level over the entire composite image. The composite image that is obtained through this process inherently contains a loss in spatial resolution in comparison to the single subject $\operatorname{SPM}\{Z\}$ and ROI-based analysis. Thus, to faithfully represent the spatial resolution of the composite, rather than present it overlaid on the template subject or line drawing, the composite is presented overlaid on similarly composited $\mathrm{T} 1$ anatomy images of all subjects (Fig. 3).

The ROI-based analysis was accomplished by first manually outlining ROIs for the entire volume of the acquisition in each subject (Fig. 3). The outlining was performed in the absence of any functional activation. Published atlases (Courchesne et al., 1989; Press et al., 1989; Press and Courchesne, 1992) were referenced to identify on each slice all relevant fissures that separate the cerebellar lobules. Lobular regions were then outlined and titled with the abbreviations used by Press and Courchesne (1992) (Table 1). These abbreviations will be used from here on in the text. All localizations were cross-validated on the sagittal acquisition. This was performed using a cross-referencing program that matched any point on the $x, y$, and $z$ coordinates in the coronal acquisition to the identical point in the sagittal acquisition (Desmond et al., 1995; Desmond and Lim, 1997). In contrast to the cerebellar lobules that can be accurately delineated, the exact borders of the cerebellar deep nuclei are not readily discernible on the MR images. The dentate nucleus (D) that is partially evident as a difference in signal contrast on the anatomical image, was outlined separately; the remaining deep nuclei are embedded within the ROI of the corpus medullare $(\mathrm{Cm})$.

After outlining of the ROIs, activations were quantified using two methods. The first was computing the mean $Z$ score in the SPM correlation $Z$ map for that ROI, and the second was computing the percentage fMRI-signal change that occurred in that ROI relative to baseline. Mean $Z$ was calculated rather than counting the number of pixels that satisfied the significance criteria used in the composite image, because using a threshold can lead to a loss of potentially important subthreshold differences in activation. The values obtained with this method are typically small, because the mean $Z$ is diluted over the large anatomical region.

\section{RESULTS}

\section{Main experiments}

Subjects responded to the detection command 40 times within a scan. Detection accuracy was computed by: ([(hits + correct rejections)/40] * 100). Detection accuracy during the scans for PROP ranged from 84 to $100 \%$ (mean 93\%) and for VAN ranged from 80 to $95 \%$ (mean $88 \%$ ). One subject was at $52 \%$ accuracy in one scan with VAN. Because performance in this scan was at chance, it was omitted from further analysis.

In the smelling tasks, both PROP and VAN induced significant activation in all subjects (all statistical tests are presented in the figure captions). Odorant-induced activation occurred primarily in the lateral hemispheres and was greater in the posterior than anterior cerebellum. The composite image revealed significant group activations for both PROP and VAN primarily in the superior portion of the semilunar lobule $(\mathrm{SeS})$, the posterior portion of the quadrangular lobule (Qup), and the inferior portion of the semilunar lobule (SeI) (Fig. 3).

By contrast, sniffing induced activation primarily in the anterior central portion of the cerebellum in all subjects. The composite image revealed significant group activations for sniffing primarily in the central lobule (C), the lobules of the anterior vermis (Ave), and the SeI (Fig. 3). Significant out-of-phase activation occurred in the posterior cerebellum during the sniffing task (out-of-phase activation reflects an increase in activation during the baseline condition in comparison to the experimental condition).

The results of the ROI-based analysis for each region for the six subjects that participated in all three basic tasks is seen in Figure 4. The mean $\operatorname{SPM}\{Z\}$ scores and percentage signal change values obtained for each region in all tasks were significantly correlated (Table 1).

The magnitude of activation in all regions was rank ordered (Table 2). Rank ordering of the activations was consistent with the composite image in showing that whereas the odorants induced activation primarily in Qup, SeI, and SeS, sniffing induced activation primarily in C, Ave, and SeI.

The SeI was highly activated by both the smelling tasks and the sniffing task (Table 2). The SeI spans from the anterior to the 


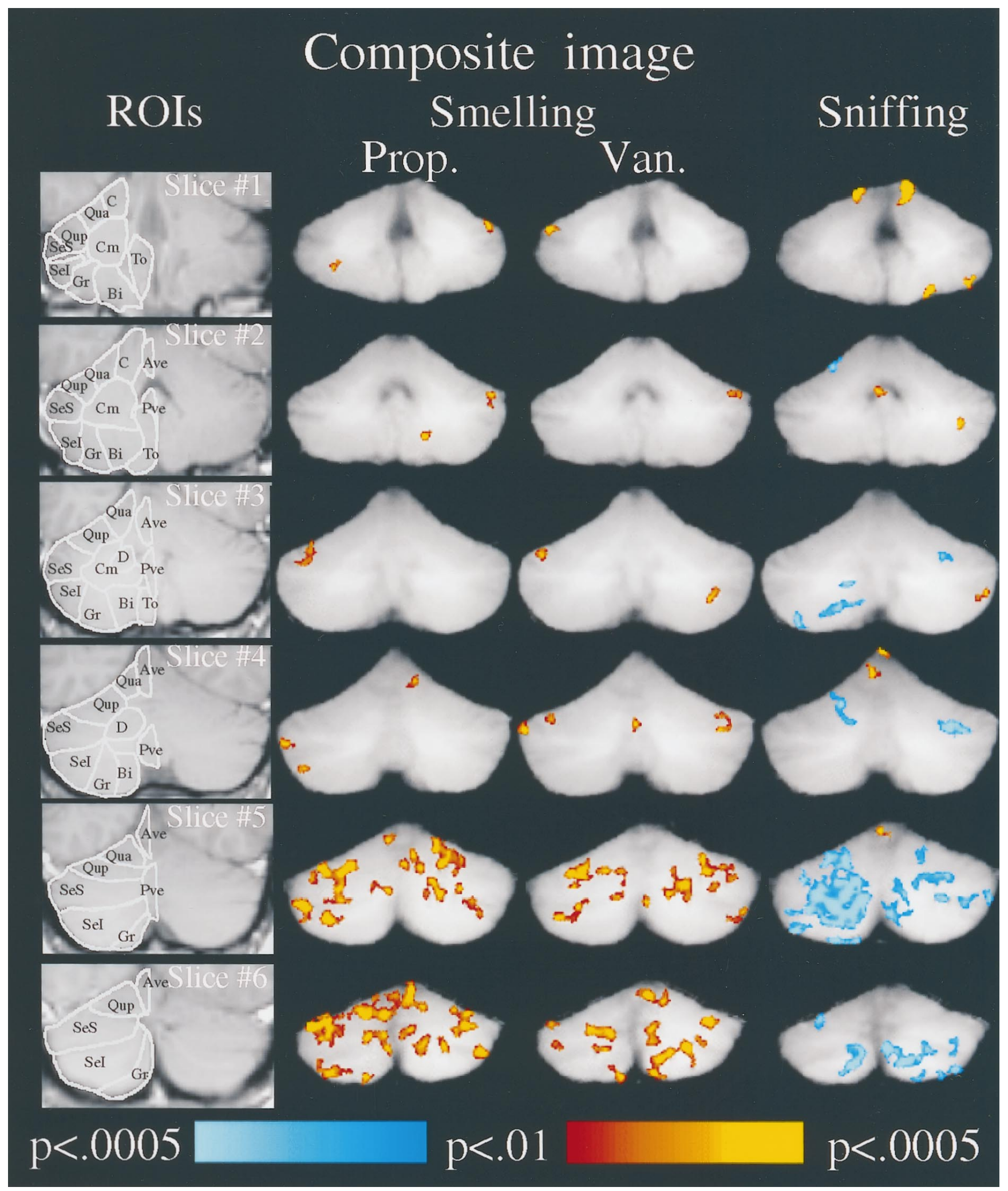

Figure 3. Composite activations overlaid on the composite anatomy of six subjects who performed all tasks. Left column is an example of the ROIs drawn for each subject shown here for the left cerebellar hemisphere, spanning from the anterior (slice \#1) to the posterior (slice \#6) cerebellum. Second column is the averaged fMRI activation induced by PROP. Third column is the averaged fMRI activation induced by VAN. Right column is the averaged fMRI activation induced by sniffing clean air. Significance of in-phase activation is color coded from red to yellow, and out-of-phase activation is coded from dark blue to light blue. The right side of the image corresponds to the right side of the brain. 


\section{Activations in all regions}

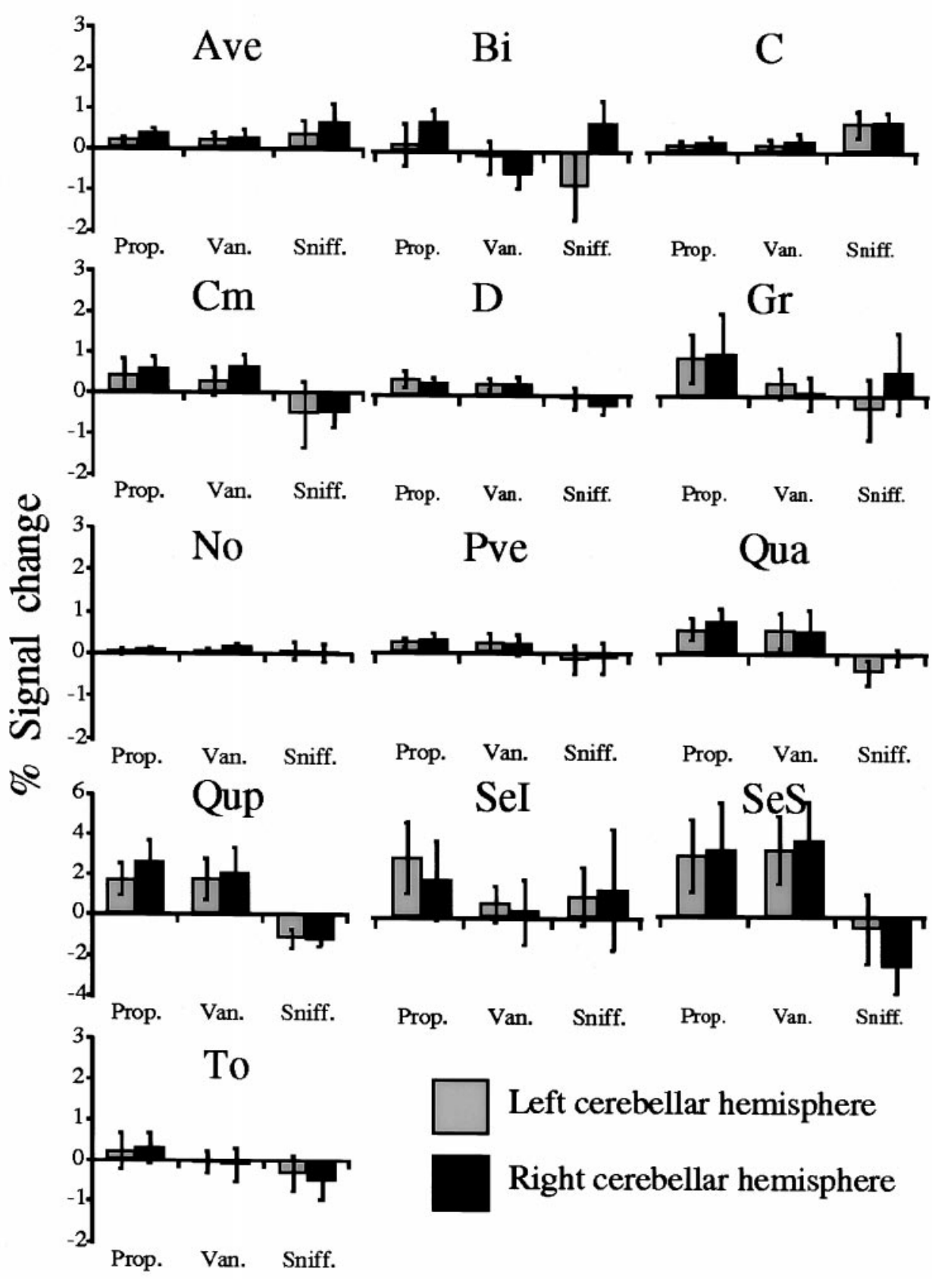

Figure 4. Percentage fMRI signal change in all 13 cerebellar regions in the six subjects who performed all three tasks. Note doubling of Y scale for Qup, SeI, and SeS from 3 to $6 \%$. Error bars are SEM. An omnibus within subject repeated-measures ANOVA with factors of region (13 ROIs), task (Prop., Van., and Sniff.), and hemisphere (left and right) revealed a significant effect for region $\left(F_{(12)}\right.$ $=2.27 ; p<0.02$ ), and a significant interaction for region $*$ task $\left(F_{(24)}=3.1 ; p=\right.$ $0.0001)$, reflecting significant differences in regions $C$ (Sniff. $>$ Van., $t_{(5)}=3.27, p=0.02$; Sniff. $>$ Prop., $\left.t_{(5)}=2.17, p=0.08\right), D$ (Prop. $>$ Sniff., $t_{(5)}=2.94, p=0.03$; Van. $>$ Sniff., $\left.t_{(5)}=2.58, p=0.05\right)$, Qua (Prop. $>$ Sniff., $t_{(5)}$ $=4.1, p=0.009$ ), Qup (Prop. $>$ Sniff., $t_{(5)}=$ $4.7, p=0.005 ;$ Van. $>$ Sniff., $t_{(5)}=2.8, p=$ 0.04), and SeS (Prop. $>$ Sniff., $t_{(5)}=3.36, p=$ 0.02 ; Van. $>$ Sniff., $\left.t_{(5)}=2.73, p=0.04\right)$.

posterior cerebellum, and the composite image suggested a dissociation within SeI, whereby sniffing induced activation primarily in the anterior portion of the SeI, and odorants induced activation primarily in the posterior portion of the SeI. To quantify this effect, the SeI was separated into an anterior portion composed of its representation in slices 1 and 2, versus a posterior portion composed of its representation in slices 5 and 6 . This separation clearly revealed that sniffing induced greater activation in the anterior portion of the SeI and the odorants induced greater activation in the posterior portion of the SeI (Fig. 5).

Whereas SeI was significantly activated during both sniffing and smelling, two other regions exhibited highly task-dependent activation: $\mathrm{C}$ was activated almost exclusively during sniffing, and $\mathrm{SeS}$ was activated almost exclusively during smelling (Table 2). These two regions significantly dissociated on these tasks (Fig. 6). This dissociation between activation induced by sniffing and activation induced by the odorants was evident in the Fourier transform of the signal-time-series in each subject (Fig. 7).

\section{Control experiments}

To assess the effects of variations in odor content on the different regions, four subjects were scanned with both high and low concentrations of PROP, and five subjects were scanned with both high and low concentrations of VAN. One of the subjects was scanned with three concentrations of PROP (Fig. 8). Activation in all regions but the biventer $(\mathrm{Bi})$ showed a trend toward con- 


\begin{tabular}{llll}
\hline \multicolumn{2}{l}{ Table 2. Rank ordering of regional activation levels } \\
PROP & VAN & Sniffing & $\begin{array}{l}\text { Concentration } \\
\text { dependence }\end{array}$ \\
\hline SeS & SeS & SeI & SeS \\
SeI & Qup & C & Qup \\
Qup & Qua & Ave & SeI \\
Gr & SeI & Gr & Gr \\
Qua & Cm & No & Cm \\
Cm & D & Bi & Qua \\
Bi & Ave & Pve & Ave \\
D & C & D & C \\
Ave & Pve & Qua & D \\
Pve & Gr & To & Pve \\
To & No & Cm & To \\
C & To & Qup & No \\
No & Bi & SeS & Bi
\end{tabular}

$\overline{\text { Regional activation was rank ordered. Spearman rank correlations revealed a non- }}$ significant positive correlation between the regions activated in the odor tasks (PROP and VAN Rho $=0.25 ; p=0.38$ ) and a nonsignificant negative correlation between the odor and sniff tasks (PROP and sniff Rho $=-0.19, p=0.5$; VAN and sniff Rho $=-0.03, p=0.89)$. Concentration dependency was positively correlated with both odor tasks (PROP Rho $=+0.69, p<0.02$; VAN Rho $=+0.64, p<0.03$ ) but nonsignificantly negatively correlated with sniffing (sniffing Rho $=-0.352 ; p=$ 0.22 ). Transformation to $Z$ values revealed that the odorant regions-concentration regions correlation was significantly greater than the sniffing regions-concentration regions correlation $(p<0.01)$.

centration dependence that was significant in D, Qua, Qup, and SeS (Fig. 9). Rank ordering of the concentration dependency of the region showed significant positive correlation with the rank order of the odor regions but a nonsignificant negative correlation with the rank order of the sniff regions (Table 2). This significant difference between the correlations shows that the regions that were more responsive to odorant presence were also more responsive to concentration changes. By contrast, regions that were more responsive to sniffing were less responsive to odorant concentration changes.

To assess the effects of sniff rate on the different regions, a single subject was scanned while sniffing at different sniff rates within the sniffing half block. Increasing sniff rate induced an increase in significant activation primarily in the anterior cerebellum in $\mathrm{C}$ and less in the posterior cerebellum (Fig. 8).

Significant out-of-phase activation occurred in the posterior cerebellum during the sniffing task, i.e., activation associated with the specific instruction not to sniff (Fig. 3, slices 5 and 6). This suggests that this activation may be related to an inhibitory process of suppressing olfactory input. To address this issue, four subjects were scanned twice, once in a sniffing task that contained the "no sniff" instruction and once in an identical sniffing task, but without the "no sniff" instruction. The only difference between these scans was that whereas in the first scan not sniffing was achieved by specifically instructing the subject not to sniff, in the second scan not sniffing was achieved merely by not instructing to sniff. Sniff rate and number were identical in these two scans. Deleting the "no sniff" instruction induced a dramatic decrease in out-of-phase activation in three of the four subjects that participated in this control (Fig. 10A).

The behavior of sniffing to the instruction "sniff" versus sniffing to the instruction "sniff and respond, is there an odor?" may not be the same. Whereas the former is purely a motor function, the latter is a motor function directed at sensory acquisition. To address any possible differences in activation related to this dif-

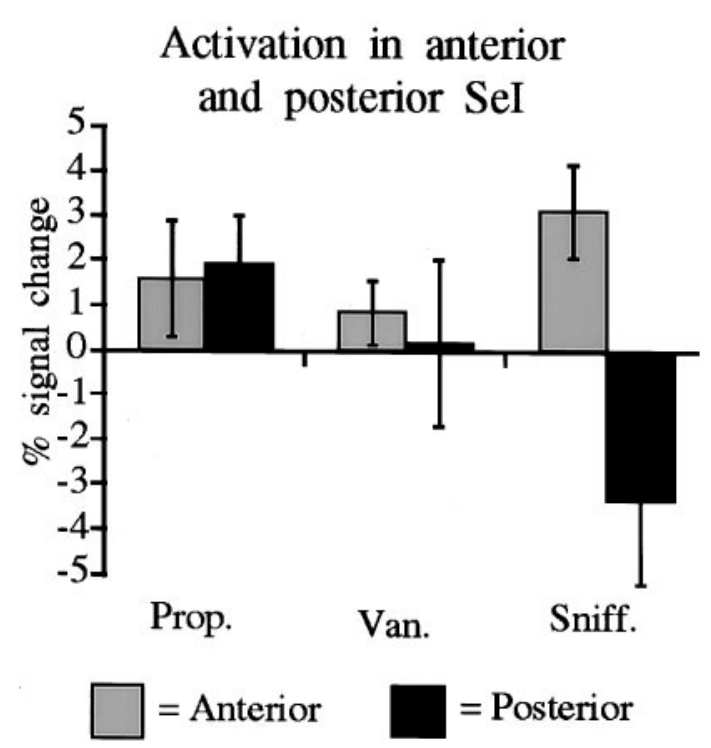

Figure 5. Activation in the anterior and posterior SeI. Activation in slices 1 and 2 was combined to form the anterior portion, and activation in slices 5 and 6 was combined to form the posterior portion. The odorants induced greater activation in the posterior than the anterior portions, and sniffing induced greater activation in the anterior than the posterior portions.

\section{Dissociation between $\mathrm{C}$ and SeS}

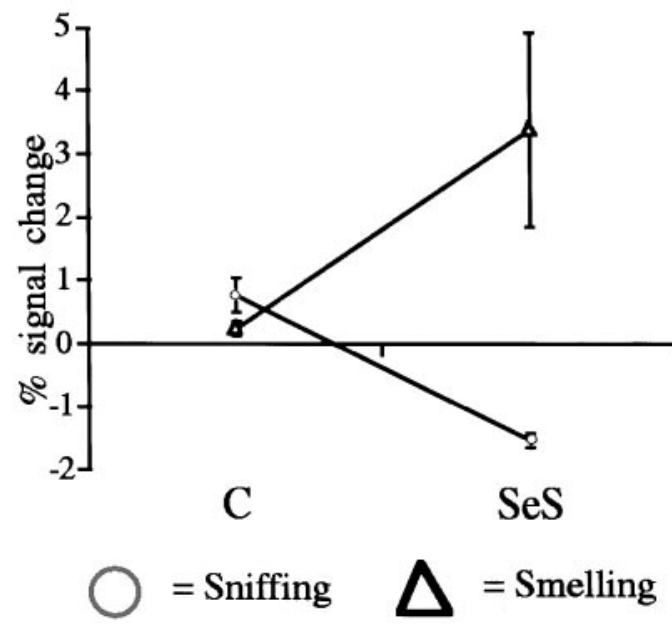

Figure 6. $\mathrm{C}$ and $\mathrm{SeS}$ dissociated in activation patterns after sniffing and smelling (odorant tasks). The two odorants were collapsed to a single smelling condition. A repeated-measures ANOVA with factors of region $(\mathrm{C}$ and $\mathrm{SeS}$ ) and task (odorants and sniffing) revealed a significant effect for task $\left(F_{(1)}=9.64 ; p=0.03\right)$ and a significant interaction for region $*$ task $\left(F_{(1)}=10.84 ; p=0.02\right)$, reflecting greater activation in the posterior region during smelling than during sniffing $\left(t_{(5)}=3.22 ; p=0.02\right)$ but greater activation in the anterior region during sniffing than during smelling $\left(t_{(5)}=2.75 ; p=0.04\right)$.

ference, four subjects were scanned twice, once at a regular sniffing task, and once at a sniffing task in which the instruction "sniff" was replaced with the instruction "sniff and respond, is there an odor?". Although there was no odorant generated in these tasks, subjects were led to believe that an odorant would be generated and were instructed to try and detect an odor that they would be questioned about after the scan. No consistent signifi- 


\section{Dissociation within a single subject within a scan}

Figure 7. Fourier transform of activity in $\mathrm{C}$ and posterior $\mathrm{SeS}$ of the same subject during the same scan. The subject sniffed once every $5 \mathrm{sec}(0.2 \mathrm{~Hz})$, and odorant presence was alternated with odorant absence every $40 \mathrm{sec}$ throughout the $320 \mathrm{sec}$ scan $(0.0125 \mathrm{~Hz})$. Whereas the primary frequency of activity in $\mathrm{C}$ is that of sniffing, the primary frequency of activity in the posterior $\mathrm{SeS}$ is that of odorant presence (smelling). The out-ofphase activation that is related to sniffing is also evident in the posterior region, but at a lower amplitude than smelling. Thus, the cerebellum is viewed here performing two tasks at two different frequencies, simultaneously.

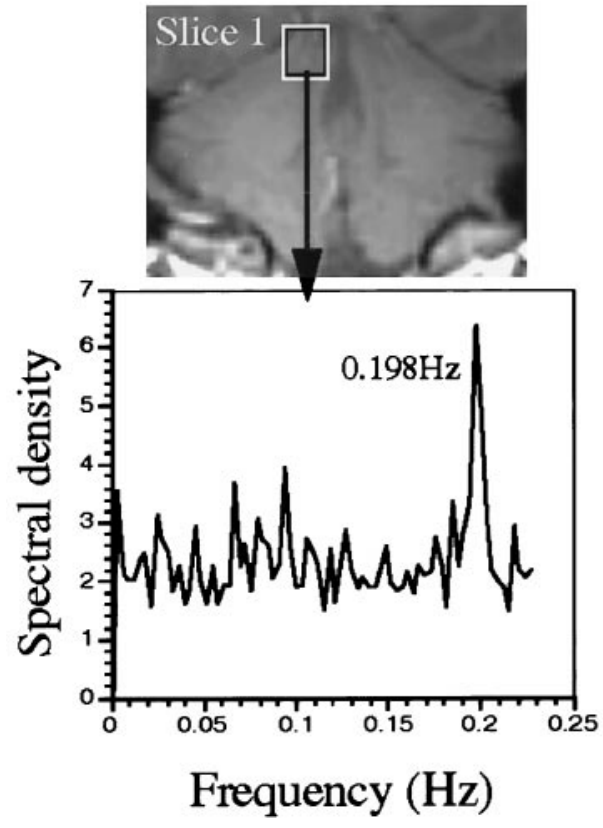

cant difference was seen in the resulting activation after these two tasks.

Natural olfactory behavior consists of sniffing. To test whether the odorant-induced activations in this study were dependent on sniffing, four subjects were scanned during passive exposure to odorants. In these experiments, subjects lay passively in the dark, did not press any buttons, and were instructed to breathe in and out only through the mouth and never through the nose. Two Teflon pipes that were inserted in the nostrils delivered $40 \mathrm{sec}$ alternating epochs of odorant and no odorant that were embedded in a constant air stream. Each subject was scanned three times, once with VAN, once with PROP, and once with an additional trigeminal odorant; citral. In three of the subjects, all nine scans revealed significant activations induced by passive smelling, in the same regions in which active smelling previously induced activation (Fig. 10B). In the fourth subject, only two of the scans (PROP and citral) induced in-phase activation, but VAN induced out-of-phase activation. In sum, 11 of the 12 scans in which passive smelling was performed induced activation in the same regions in which active smelling induced activation.

In a final control, a "sham" scan was performed, in which a subject performed the smelling task, i.e., constantly sniffing and trying to detect an odorant, but no odorant was generated. This scan was identical in behavior to the pure sniffing scans, but it was analyzed at the frequency of previous odor presentations rather than at the frequency of sniffing. This was done to test for noise at that frequency $(0.0125 \mathrm{~Hz})$. No significant activation was evident in this scan in any region of the cerebellum (this control was also replicated by later reanalyzing the sniffing tasks at the 0.0125 $\mathrm{Hz}$ frequency).

\section{DISCUSSION}

These results demonstrate that the cerebellum is involved in olfaction in the human. Both the composite $\operatorname{SPM}\{Z\}$ map and the individual ROI-based analysis were consistent in showing that the posterior lateral cerebellar hemispheres were significantly activated by odorants. This activation was concentrationdependent and independent of sniffing. Whereas PROP stimulates both the trigeminal and olfactory nerves (Kendal-Reed et al., 1998), VAN stimulates only the olfactory nerve (Doty et al., 1978). No significant differences were observed between the activations induced by the two odorants.

Odorant-induced activation patterns appeared somewhat patchy. It is tempting to relate this patchiness to the patchy organization of the granule cell layer and the resulting fractured patterns of activity that represent the somatotopy of tactile projections to the cerebellum (Shambes et al., 1978; Bower et al., 1981). It is unclear, however, if this patchiness could be represented at the spatial resolution of fMRI.

Whereas odorants induced activation primarily in the posterior lateral regions, sniffing induced activation primarily in the anterior central regions. During the sniffing condition, significant out-of-phase activation was evident in the posterior cerebellum, medially to the odorant activations. This activation was induced by the instruction not to sniff. Deleting the "no sniff" instruction dramatically reduced this activation. The latter leads us to propose that this activation reflects the active process of inhibiting olfactory exploration. The activation differences between not sniffing when specifically told not to, versus not sniffing just because no instruction to do so was generated, constitute an intriguing example of attentional effects on cerebellar activation. This effect resembles activity that occurs in motor association regions after merely anticipating or rehearsing a movement without actually performing it (Evarts and Tanji, 1974; Tanji and Evarts, 1976; Roland et al., 1987; Decety, 1996).

Might all the activations in this study be related to inhibiting olfactory exploration? One could raise the concern that although subjects were instructed to maintain an identical sniff throughout the odorant and no odorant conditions, they may not have successfully followed this instruction. Thus, a sniff when an odorant was present may have been inhibited in comparison to a sniff 


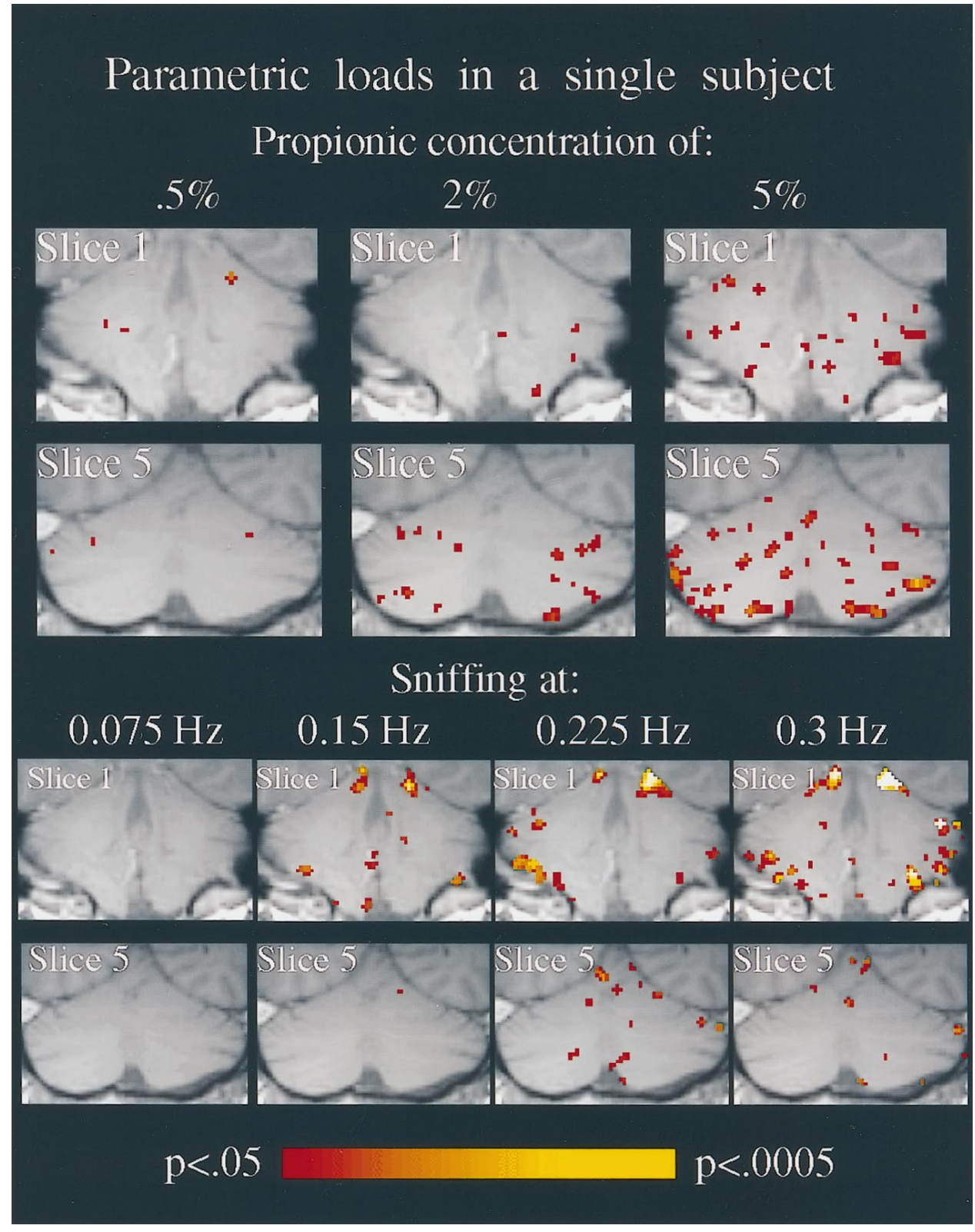

Figure 8. $\operatorname{SPM}\{Z\}$ s of anterior and posterior slices of a single subject during separate scans in which either odor concentration or sniff rate were varied parametrically. Activation was both odor concentration- and sniff rate-dependent. A greater odor concentration dependency is evident in the posterior versus the anterior slice, and greater sniff rate dependency is evident in the anterior versus the posterior slice. Note that only in-phase activation is shown in this figure. without an odorant, because an increase in odorant concentration induces a sniff of lesser volume (Laing, 1983). Such limiting of a sniff would result in an increase in activation, as seen in the form of out-of-phase activation in the sniffing tasks. Thus, we may erroneously attribute activation to the presence of an odorant when it is actually related to inhibiting sniffing (because of the presence of that odorant). The latter concern was largely negated by the passive task: The presence of an odorant induced activation in the cerebellum in the absence of any motor function, sniffing included. The activation induced by passive smelling was less robust than that induced by odorants perceived via a sniff. In fact, we have found that passive smelling does not induce a consistent fMRI signal in primary olfactory cortex [the latter, however, may be related to the possibility of temporal encoding of odor information in the ventral temporal areas that would not induce increased activation as assessed with these methods (Sobel et al., 1998)]. That said, the remote possibility remains that the activation was related to the intention to inhibit the sniff once an odorant was perceived, regardless of whether the sniff was ultimately executed or not.

What may be the role of the cerebellum in olfaction? The following is a working hypothesis: sniff volume is inversely proportional to odor concentration (Laing, 1983). Maintaining this inverse proportionality calls for an accurate rapid feedback mechanism that monitors the sensory input (odor concentration) and modulates the motor output (sniff volume). Cerebellar maintenance of such feedback mechanisms has been extensively described for tactile information, as well as other senses, like the cerebellum receiving sensory information regarding retinal slip to then effect the vestibulo-ocular reflex to reduce that slip (Robinson, 1976; Lisberger and Sejnowski, 1992), and like the cerebellum receiving auditory input that may then effect the pinna, thus modulating further auditory input (suggested by Bower 1997; see also Huang et al., 1991; Cicirata et al., 1992; Young et al., 1992). Here we suggest that the cerebellum is receiving olfactory information for modulating the sniff, which in turn modulates further 


\section{Concentration dependence}

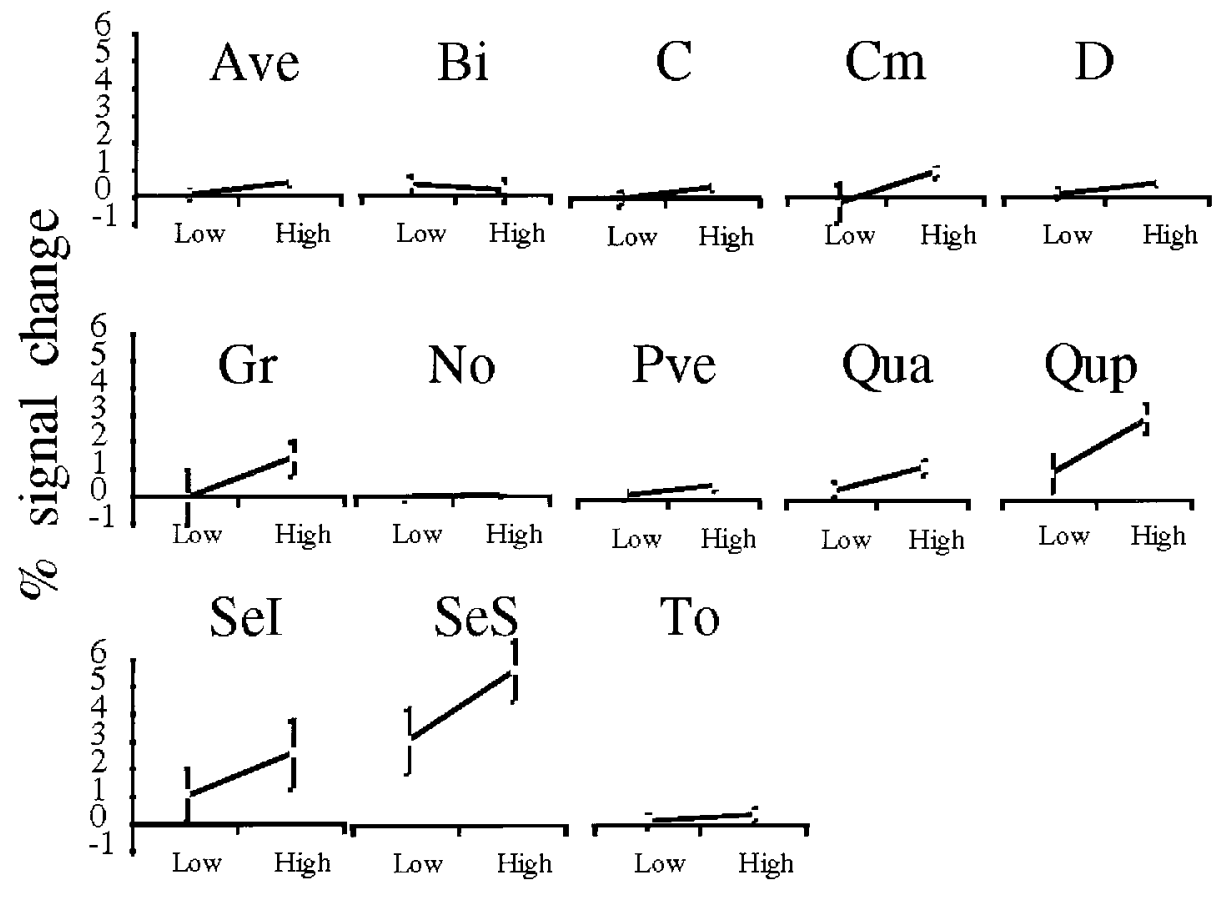

Figure 9. Concentration dependence in all 13 regions. The difference in fMRI response to the high versus the low concentration of the odorants was significant in regions $D\left(t_{(8)}=2.5\right.$; $p=0.04)$, Qua $\left(t_{(8)}=2.7 ; p=0.03\right)$, Qup $\left(t_{(8)}=3.2 ; p=0.01\right)$, and $\operatorname{SeS}\left(t_{(8)}=3.3\right.$;

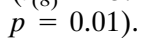

olfactory input. In this capacity, the cerebellum could be subserving maintenance of the Teghtsoonian model of olfactory size constancy (Teghtsoonian et al., 1978).

By which pathway may the olfactory information reach the cerebellum? Whereas well described trigeminal projections to the cerebellum (Yatim et al., 1996) may explain activation induced by PROP, a candidate pathway for both PROP and VAN is less evident. Olfactory information is initially projected from the olfactory bulb directly to primary olfactory cortex (piriform) (Price, 1990). Olfactory projections are then widely spread within the ventral temporal region and throughout the brain. Although a well described candidate pathway would be the hypothalamocerebellar fibers (Haines et al., 1997), a pathway that traverses primary olfactory cortex is also available. The ventral tegmental area (VTA) in the rat is strongly interconnected to primary olfactory cortex (Oades and Halliday, 1987). Using double labeling, Ikai et al. (1992) first found projections from the VTA of the rat to the cerebellar cortex and lateral cerebellar nucleus, and later single neurons in the VTA that project collaterals to both piriform cortex and the cerebellum (Ikai et al., 1994). As these authors note, the dopaminergic axons of VTA neurons project to the pontocerebellum, which also subserves programming and coordination of voluntary motor behaviors. This circuit that contains a direct connection between primary olfactory cortex and the cerebellum is a well suited candidate to control the sniffvolume odorant-concentration feedback mechanism that we have proposed. Thus, odor information may be relayed from primary olfactory cortex to the posterior lateral cerebellum; based on odor content, cerebellar circuits would then determine optimal sniff volume for further odorant sampling. Cerebellar efferents would then modulate sniff parameters.

In what way do our findings relate to the ongoing debate regarding the role of the cerebellum? The role we have suggested for the cerebellum in olfaction supports the model proposed by Bower et al. (1981), suggesting that the cerebellum coordinates acquisition of sensory information. For tactile information, Bower (1997) proposed that "the cerebellum is responsible for monitoring incoming sensory data from these surfaces and adjusting their positions relative to each other and relative to the object being explored, in real time". Here too, we suggest that the cerebellum is monitoring incoming data (odorant concentration) and adjusting the position of the stimulus (odorant air stream) relative to the sensory surface (olfactory epithelium) by controlling the motor behavior (sniff), in real time. That said, our findings may still be incorporated within other models of cerebellar function noted in the introduction, as here to, there is an element of timing, an element of attentional modulation, and most importantly, an element of feedback for motor control.

The cerebellar model of Bower et al. (1981) was supported in an fMRI study in which an increase in dentate activation was seen during a tactile stimulation task when it included an element of tactile discrimination (Gao et al., 1996). We, therefore, expected an increase in dentate activation when sniffing in response to the "sniff and respond, is there an odor" instruction in comparison to sniffing to the "sniff" instruction. In the four subjects that participated in this task, two showed an increase in dentate activation, and two showed a decrease. Whereas the latter finding does not support the Bower (1981) model, it may be attributed to that in the context of an olfaction experiment, subjects may be searching for odorants even in a scan in which they are instructed just to sniff and informed that no odorants will be present.

If the cerebellum plays a role in olfactory processing, one would expect an olfactory deficit in patients with cerebellar lesions. To the best of our knowledge, in every disease in which there is cerebellar damage and olfaction has been tested, an olfactory deficit has been found [e.g., Alzheimer's disease (olfactory deficit [OD]: Moberg et al., 1987; Doty et al., 1991; cerebellar damage (CD): Joachim et al., 1989); Parkinson's disease (OD: Doty et al., 1988; CD: Heimburger, 1969), Korsakoff (OD: Jones et al., 1975; CD: Butterworth, 1993; Shear et al., 1996), schizo- 


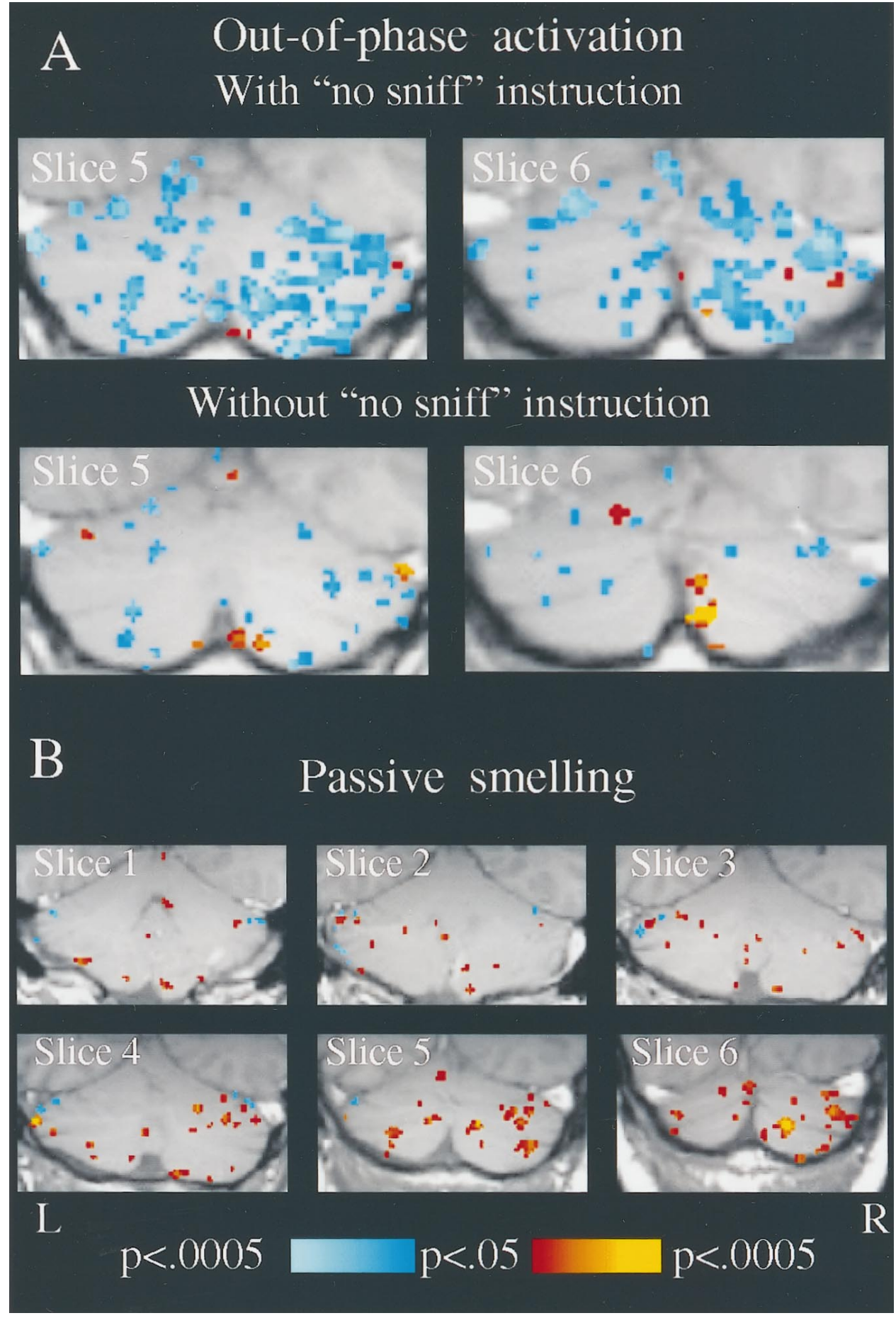

Figure 10. $A, \operatorname{SPM}\{Z\} \mathrm{s}$ of the posterior cerebellum of a single subject during sniffing in a task balanced with a "no sniff" instruction versus a task sniffing without a "no sniff" instruction. The "no sniff" instruction induced a significant increase in out-of-phase activation. This effect was evident in three of the four subjects tested. Deleting the "no sniff" instruction induced a mean reduction of $26.4 \%$ in out-of-phase activity in the four subjects. $B, \operatorname{SPM}\{Z\}$ map of a single subject during passive stimulation with an odorant. No motor action was performed during this scan. phrenia (OD: Kopala et al., 1994; CD: Taylor, 1991; Deshmukh et al., 1997), multiple sclerosis (OD: Doty et al., 1997; CD: Seitelberger, 1973; Davie et al., 1995), and alcoholism (OD: Ditraglia et al., 1991; CD: Gilman et al., 1990; Shear et al., 1996)]. We do not intend to imply that the cerebellar lesion is primarily or even largely responsible for the olfactory deficit in these diseases. Indeed, some of the above diseases include specific damage to primary olfactory structures outside of the cerebellum. We do suggest, however, that cerebellar lesions may contribute to olfactory deficits in these diseases [in keeping with the notion of the cerebellum as important but not necessary in maintaining various functions (Thach, 1996; Bower, 1997)].

\section{REFERENCES}

Adrian ED (1942) Olfactory reactions in the brain of the hedgehog. J Physiol (Lond) 100:459-473.

Akshoomoff NA, Courchesne E, Townsend J (1997) Attention coordination and anticipatory control. Int Rev Neurobiol 41:575-598.

Allen G, Buxton RB, Wong EC, Courchesne E (1997) Attentional activation of the cerebellum independent of motor involvement. Science 275:1940-1943.

Bloedel JR (1973) Cerebellar afferent systems: a review. Prog Neurobiol 2:3-68.

Bloedel JR, Bracha V (1997) Duality of cerebellar motor and cognitive functions. Int Rev Neurobiol 41:613-634.

Bower JM (1997) Control of sensory data acquisition. Int Rev Neurobiol 41:489-513. 
Bower JM, Beermann DH, Gibson JM, Shambes GM, Welker W (1981) Principles of organization of a cerebro-cerebellar circuit: Micromapping the projections from cerebral (SI) to cerebellar (granule cell layer) tactile areas of rats. Brain Behav Evol 18:1-18.

Butterworth RF (1993) Pathophysiology of cerebellar dysfunction in the Wernicke-Korsakoff syndrome. Can J Neurol Sci 20:S123-S126.

Cicirata F, Angaut P, Serapide MF, Panto MR, Nicotra G (1992) Multiple representation in the nucleus lateralis of the cerebellum: an electrophysiologic study in the rat. Exp Brain Res 89:352-362.

Colebatch JG, Adams L, Murphy K, Martin AJ, Lammertsma AA, Tochon-Danguy HJ, Clark JC, Friston KJ, Guz A (1991) Regional cerebral blood flow during volitional breathing in man. J Physiol (Lond) 443:91-103.

Courchesne E, Press GA, Murakami J, Berthoty D, Grafe M, Wiley CA, Hesselink JR (1989) The cerebellum in sagittal plane-anatomic-MR correlation: 1. The vermis. AJR Am J Roentgenol 153:829-835.

Courchesne E, Townsend J, Akshoomoff NA, Saitoh O, YeungCourchesne R, Lincoln AJ, James HE, Haas RH, Schreibman L, Lau $\mathrm{L}$ (1994) Impairment in shifting attention in autistic and cerebellar patients. Behav Neurosci 108:848-865.

Davie CA, Barker GJ, Webb S, Tofts PS, Thompson AJ, Harding AE, McDonald WI, Miller DH (1995) Persistent functional deficit in multiple sclerosis and autosomal dominant cerebellar ataxia is associated with axon loss. Brain 118:1583-1592.

Decety J (1996) Do imagined and executed actions share the same neural substrate? Brain Res Cogn Brain Res 3:87-93.

Deshmukh A, Sullivan EV, Mathalon DH, Desmond JE, Lim KO, Pfefferbaum A (1997) Regional cerebellar volume deficits in schizophrenia, alcoholism, and schizophrenia with alcohol comorbidity. Schizophr Res 24:142-143.

Desmond JE, Lim KO (1997) On- and offline Talairach registration for structural and functional MRI studies. Hum Brain Mapp 5:58-73.

Desmond JE, Sum JM, Wagner AD, Demb JB, Shear PK, Glover GH, Gabrieli JD, Morrell MJ (1995) Functional MRI measurement of language lateralization in Wada-tested patients. Brain 118:1411-1419.

Desmond JE, Gabrieli JD, Wagner AD, Ginier BL, Glover GH (1997) Lobular patterns of cerebellar activation in verbal working-memory and finger-tapping tasks as revealed by functional MRI. J Neurosci 17:9675-9685.

Desmond JE, Gabrieli JDE, Glover GH (1998) Dissociation of frontal and cerebellar activity in a cognitive task: evidence for a distinction between selection and search. NeuroImage 7:368-376.

Ditraglia GM, Press DS, Butters N, Jernigan TL, Cermak LS, Velin RA, Shear PK, Irwin M, Schuckit M (1991) Assessment of olfactory deficits in detoxified alcoholics. Alcohol 8:109-115.

Doty RL, Brugger WE, Jurs PC, Orndorff MA, Snyder PJ, Lowry LD (1978) Intranasal trigeminal stimulation from odorous volatiles: Psychometric responses from anosmic and normal humans. Physiol Behav 20:175-185.

Doty RL, Deems DA, Stellar S (1988) Olfactory dysfunction in parkinsonism: a general deficit unrelated to neurologic signs, disease stage, or disease duration. Neurology 38:1237-1244.

Doty RL, Perl DP, Steele JC, Chen KM, Pierce JD Jr, Reyes P, Kurland LT (1991) Olfactory dysfunction in three neurodegenerative diseases. Geriatrics 46:47-51.

Doty RL, Li C, Mannon LJ, Yousem DM (1997) Olfactory dysfunction in multiple sclerosis. N Engl J Med 336:1918-1919.

Evarts EV, Tanji J (1974) Gating of motor cortex reflexes by prior instruction. Brain Res 71:479-494.

Fiez JA (1996) Cerebellar contributions to cognition. Neuron 16:13-15.

Friston KJ, Jezzard P, Turner R (1994) Analysis of functional MRI time-series. Hum Brain Mapp 1:153-171.

Friston KJ, Williams S, Howard R, Frackowiak RS, Turner R (1996) Movement-related effects in fMRI time-series. Magn Reson Med 35:346-355.

Gao JH, Parsons LM, Bower JM, Xiong J, Li J, Fox PT (1996) Cerebellum implicated in sensory acquisition and discrimination rather than motor control. Science 272:545-547.

Gilman S, Adams K, Koeppe RA, Berent S, Kluin KJ, Modell JG, Kroll P, Brunberg JA (1990) Cerebellar and frontal hypometabolism in alcoholic cerebellar degeneration studied with positron emission tomography. Ann Neurol 28:775-785.

Glover GH, Lai S (1998) Self-navigated spiral fMRI: interleaved versus single-shot. Magn Reson Med 39:361-368.
Hahn I, Scherer PW, Mozell MM (1994) A mass transport model of olfaction. J Theor Biol 167:115-128.

Haines DE, Dietrichs E, Mihailoff GA, McDonald EF (1997) The cerebellar-hypothalamic axis: basic circuits and clinical observations. Int Rev Neurobiol 41:83-107.

Heimburger RF (1969) The role of the cerebellar nuclei in dyskinetic disorders. Confin Neurol 31:57-69.

Horne MK, Butler EG (1995) The role of the cerebello-thalamo-cortical pathway in skilled movement. Prog Neurobiol 46:199-213.

Huang CM, Liu GL (1991) Auditory responses in the posterior vermis of the cat: the buried cerebellar cortex. Brain Res 553:201-205.

Huang CM, Liu GL, Yang BY, Mu H, Hsiao CF (1991) Auditory receptive area in the cerebellar hemisphere is surrounded by somatosensory areas. Brain Res 541:252-256.

Ikai Y, Takada M, Shinonaga Y, Mizuno N (1992) Dopaminergic and non-dopaminergic neurons in the ventral tegmental area of the rat project, respectively, to the cerebellar cortex and deep cerebellar nuclei. Neuroscience 51:719-728.

Ikai Y, Takada M, Mizuno N (1994) Single neurons in the ventral tegmental area that project to both the cerebral and cerebellar cortical areas by way of axon collaterals. Neuroscience 61:925-934.

Ito M (1984) The cerebellum and neural control. New York: Raven.

Ivry R (1997) Cerebellar timing systems. Int Rev Neurobiol 41:555-573.

Joachim CL, Morris JH, Selkoe DJ (1989) Diffuse senile plaques occur commonly in the cerebellum in Alzheimer's disease. Am J Pathol 135:309-319.

Jones BP, Moskowitz RH, Butters N (1975) Olfactory discrimination in alcoholic Korsakoff patients. Neuropsychologia 13:173-179.

Kendal-Reed M, Walker JC, Morgan WT, LaMacchio M, Lutz RW (1998) Human responses to prop. acid. I. Quantification of within- and between-participant variation in perception by normosmics and anosmics. Chem Senses 23:71-82.

Kim SG, Ugurbil K, Strick PL (1994) Activation of a cerebellar output nucleus during cognitive processing. Science 265:949-951.

Kopala LC, Good KP, Honer WG (1994) Olfactory hallucinations and olfactory identification ability in patients with schizophrenia and other psychiatric disorders. Schizophr Res 12:205-211.

Laing DG (1983) Natural sniffing gives optimum odor perception for humans. Perception 12:99-117.

Lisberger SG (1988) The neural basis for learning of simple motor skills. Science 242:728-735.

Lisberger SG, Sejnowski TJ (1992) Motor learning in a recurrent network model based on the vestibulo-ocular reflex. Nature 360:159-161.

Lisberger SG, Pavelko TA, Bronte-Stewart HM, Stone LS (1994) Neural basis for motor learning in the vestibuloocular reflex of primates. II Changes in the responses of horizontal gaze velocity Purkinje cells in the cerebellar flocculus and ventral paraflocculus. J Neurophysiol 72:954-973.

Le Magnen J (1945) Etude des facteurs dynamiques de l'excitation olfactive. L'Année Psychologique. 77-89.

Mansfeld G, Tyukody V (1936) Atemzentrum und narkose. Arch Int Pharmacodyn Ther 54:219.

Moberg PJ, Pearlson GD, Speedie LJ, Lipsey JR, Strauss ME, Folstein SE (1987) Olfactory recognition: differential impairments in early and late Huntington's and Alzheimer's diseases. J Clin Exp Neuropsychol 9:650-664.

Mozell MM, Hornung DE, Leopold DA, Youngentob SL (1983) Initial mechanisms basic to olfactory perception. Am J Otolaryngol 4:238-245.

Oades RD, Halliday GM (1987) Ventral tegmental (A10) system: neurobiology. 1. Anatomy and connectivity. Brain Res 434:117-165.

Parsons LM, and Fox PT (1997) Sensory and cognitive functions. Int Rev Neurobiol 41:255-271.

Paulin MG (1997) Neural representations of moving systems. Int Rev Neurobiol 41:515-533.

Petersen SE, Fox PT, Posner MI, Mintun M, Raichle ME (1988) Positron emission tomographic studies of the cortical anatomy of single-word processing. Nature 331:585-589.

Poldrack RA, Desmond JE, Glover GH, Gabrieli JD (1998) The neural basis of visual skill learning: an fMRI study of mirror reading. Cereb Cortex 8:1-10.

Press GA, Courchesne E (1992) Atlas of cerebellar hemispheres and vermis. In: Clinical brain imaging (Hayman LA, Hinck VC, eds), pp 251-286. St. Louis: Mosby Year Book.

Press GA, Murakami J, Courchesne E, Berthoty DP, Grafe M, Wiley CA, 
Hesselink JR (1989) The cerebellum in sagittal plane-anatomic-MR correlation: 2. The cerebellar hemispheres. AJR Am J Roentgenol 153:837-846

Price JL (1990) Olfactory system. In: The human nervous system (Paxinos G, ed), pp 979-1001. San Diego: Academic.

Raichle ME, Fiez JA, Videen TO, MacLeod AM, Pardo JV, Fox PT, Petersen SE (1994) Practice-related changes in human brain functional anatomy during nonmotor learning. Cereb Cortex 4:8-26.

Rehn T (1978) Perceived odor intensity as a function of air flow through the nose. Sens Processes 2:198-205.

Robinson DA (1976) Adaptive gain control of vestibulo-ocular reflex by the cerebellum. J Neurophysiol 39:954-969.

Roland PE, Eriksson L, Stone-Elander S, Widen L (1987) Does mental activity change the oxidative metabolism of the brain? J Neurosci 7:2373-2389.

Schmahmann JD (1997) Rediscovery of an early concept. Int Rev Neurobiol 41:3-27.

Schmahmann JD, Sherman JC (1998) The cerebellar cognitive affective syndrome. Brain 121:561-579.

Seitelberger F (1973) Pathology of multiple sclerosis. Ann Clin Res $5: 337-344$

Shambes GM, Beermann DH, Welker W (1978) Multiple tactile areas in cerebellar cortex: another patchy cutaneous projection to granule cell columns in rats. Brain Res 157:123-128.

Shear PK, Sullivan EV, Lane B, Pfefferbaum A (1996) Mammillary body and cerebellar shrinkage in chronic alcoholics with and without amnesia. Alcohol Clin Exp Res 20:1489-1495.

Snider RS, Eldred E (1948) Cerebral projections to the tactile, auditory, and visual areas of the cerebellum. Anat Rec 100:82.

Sobel N, Prabhakaran V, Desmond J, Glover G, Goode RL, Sullivan E, Gabrieli JDE (1998) Sniffing and smelling: separate subsystems in the human olfactory cortex. Nature 392:282-286.

Sobel N, Prabhakaran V, Desmond J, Glover G, Sullivan E, Gabrieli JDE (1997a) Separate cerebellar components subserve sniffing and smelling. Paper presented at Society for Neuroscience 27th Annual Meeting, Washington, DC, November.

Sobel N, Prabhakaran V, Desmond J, Glover G, Sullivan E, Gabrieli JDE (1997b) A method for functional magnetic resonance imaging of olfaction. J Neurosci Methods 78:115-121.
Stein JF, Glickstein M (1992) Role of the cerebellum in visual guidance of movement. Physiol Rev 72:967-1017.

Tanji J, Evarts EV (1976) Anticipatory activity of motor cortex neurons in relation to direction of an intended movement. J Neurophysiol 39:1062-1068.

Taylor, MA (1991) The role of the cerebellum in the pathogenesis of schizophrenia. Neuropsychiatry Neuropsychol Behav Neurol 4:251-280.

Teghtsoonian R, Teghtsoonian M, Berglund B, Berglund U (1978) Invariance of odor strength with sniff vigor: an olfactory analogue to size constancy. J Exp Psychol Hum Percept Perform 4:144-152.

Thach WT (1996) On the specific role of the cerebellum in motor learning and cognition: clues from PET activation and lesion studies in man. Behav Brain Sci 19:411-431.

Thach WT, Goodkin HP, Keating JG (1992) The cerebellum and the adaptive coordination of movement. Annu Rev Neurosci 15:403-442.

Williams RW, Herrup K (1988) The control of neuron number. Annu Rev Neurosci 11:423-453.

Woods RP, Cherry SR, Mazziotta JC (1992) A rapid automated algorithm for accurately aligning and re-slicing positron emission tomography images. J Comput Assist Tomogr 16:620-633.

Xiong J, Gao JH, Lancaster JL, Fox PT (1995) Clustered pixels analysis for functional MRI activation studies of the human brain. Hum Brain Mapp 3:287-301.

Yatim N, Billig I, Compoint C, Buisseret P, Buisseret-Delmas C (1996) Trigeminocerebellar and trigemino-olivary projections in rats. Neurosci Res 25:267-283.

Young ED, Spirou GA, Rice JJ, Voigt HF (1992) Neural organization and responses to complex stimuli in the dorsal cochlear nucleus. Philos Trans R Soc Lond B Biol Sci 336:407-413.

Youngentob SL, Mozell MM, Sheehe PR, Hornung DE (1987) A quantitative analysis of sniffing strategies in rats performing odor detection tasks. Physiol Behav 41:59-69.

Yousem DM, Williams SC, Howard RO, Andrew C, Simmons A, Allin M, Geckle RJ, Suskind D, Bullmore ET, Brammer MJ, Doty RL (1997) Functional MR imaging during odor stimulation: preliminary data. Radiology 204:833-838. 